\title{
Regular dipyridamole therapy produces sustained protection against cardiac ischemia-reperfusion injury: is it time to revisit PARIS?
}

\author{
Vincent M. Figueredo, M.D. \\ Thomas Jefferson University \\ Chika Okusa \\ Osaka Dental University \\ Kazuhiro Kaneda \\ Osaka Dental University \\ Yoshitaka Inamura

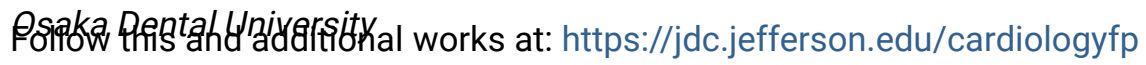 \\ Irarnibityeanatology Commons \\ pseqa Pestakfniorsithow access to this document benefits you
}

\section{Recommended Citation}

Figueredo, M.D., Vincent M.; Okusa, Chika; Kaneda, Kazuhiro; Inamura, Yoshitaka; and Miyamae, Masami, "Regular dipyridamole therapy produces sustained protection against cardiac ischemia-reperfusion injury: is it time to revisit PARIS?" (2014). Division of Cardiology Faculty Papers. Paper 50.

https://jdc.jefferson.edu/cardiologyfp/50

This Article is brought to you for free and open access by the Jefferson Digital Commons. The Jefferson Digital Commons is a service of Thomas Jefferson University's Center for Teaching and Learning (CTL). The Commons is a showcase for Jefferson books and journals, peer-reviewed scholarly publications, unique historical collections from the University archives, and teaching tools. The Jefferson Digital Commons allows researchers and interested readers anywhere in the world to learn about and keep up to date with Jefferson scholarship. This article has been accepted for inclusion in Division of Cardiology Faculty Papers by an authorized administrator of the Jefferson Digital Commons. For more information, please contact: JeffersonDigitalCommons@jefferson.edu. 


\title{
REGULAR DIPYRIDAMOLE THERAPY PRODUCES SUSTAINED PROTECTION AGAINST CARDIAC ISCHEMIA-REPERFUSION INJURY: IS IT TIME TO REVISIT PARIS?
}

\author{
Vincent M. Figueredo $\mathrm{MD}^{1,2^{*}}$, Chika Okusa DDS, $\mathrm{PhD}^{3 *}$, \\ Kazuhiro Kaneda DDS, $\mathrm{PhD}^{3}$, Yoshitaka Inamura DDS, $\mathrm{PhD}^{3}$, \\ Masami Miyamae $\mathrm{MD}, \mathrm{PhD}^{4}$
}

Einstein Institute for Heart and Vascular Health, Einstein Medical Center, Philadelphia ${ }^{1}$; Jefferson Medical College, Thomas Jefferson University, Philadelphia ${ }^{2}$; Department of Anesthesiology ${ }^{3}$ and Internal Medicine ${ }^{4}$, Osaka Dental University, Osaka, Japan

*V.M.F. and C.O. equally contributed to this work.

Key Words: dipyridamole, adenosine, endothelial nitric oxide synthase, Akt, ischemia-reperfusion injury, preconditioning, guinea pig

Running Title: Dipyridamole therapy and ischemia-reperfusion injury

Author for Correspondence:

Masami Miyamae, MD, PhD

Department of Internal Medicine,

Osaka Dental University

8-1 Kuzuha hanazono-cho Hirakata,

Osaka 573-1121, Japan

TEL: 81-72-864-3079, FAX: 81-72-864-3179

E-mail: miyamae0907@gmail.com 


\section{Abstract}

Emergent coronary reperfusion therapies are rarely carried out before considerable myocardial injury has occurred. Moreover, reperfusion after prolonged ischemia produces paradoxical ischemia-reperfusion injury, attenuating the efficacy of reperfusion therapies. This has provided impetus for identifying chronic therapies to protect against ischemia-reperfusion injury in those at risk. We previously found regular dipyridamole therapy produces a chronic preconditioning-like effect mediated through adenosine A1 receptors. To determine how long this chronic preconditioning effect of dipyridamole remains present after discontinuing therapy, guinea pigs received $4 \mathrm{mg} / \mathrm{kg} /$ day in their water for 6 weeks. Ischemia-reperfusion was performed at $0,2,3$, and 4 days after dipyridamole discontinuation (0Day, 2Days, 3Days and 4Days; $n=8$ per group). Left ventricular developed pressure (LVDP), end-diastolic pressure (LVED), coronary flow (CF), infarct size, and western blot analyses for Akt and endothelial nitric oxide synthase (eNOS) were studied. After ischemia-reperfusion, 0Day, 2Days and 3Days, but not 4Days, had significantly higher LVDP and lower LVDEP compared to control. Myocardial infarct size was significantly reduced at 0Day, 2Days and 3Days, but not 4Days, compared to control. Western blot analyses demonstrated upregulation of phospho-Akt and phospho-eNOS expression at 0Day, 2Days, 3Days, but not 4Days. A chronic preconditioning-like cardioprotection by regular dipyridamole treatment persists for 3 days after discontinuing therapy. Increased activated Akt and eNOS expression may play a role in this persistent cardioprotection. 
The Persantine-Aspirin Reinfarction Study (PARIS) Research Group examined the efficacy of Persantine (dipyridamole $75 \mathrm{mg}$ ) in combination with aspirin (324 mg) versus aspirin alone or placebo for preventing reinfarction in 2026 patients with a prior history of myocardial infarction in the preceding 8 weeks to 5 years[1]. No significant differences were observed between dipyridamole plus aspirin versus aspirin alone in total mortality, coronary mortality, or nonfatal myocardial infarction (MI). However, patients were followed from 1975 to 1979, before revascularization procedures were widely available. Follow up studies and meta-analyses also supported the lack of benefit of adding dipyridamole to aspirin to prevent cardiovascular events, with the possible exception of strokes in at risk patients.

Acute MI's are now routinely treated with emergent reperfusion therapies. However, these reperfusion therapies are rarely carried out before considerable myocardial injury has occurred. Moreover, reperfusion after prolonged ischemia produces a paradoxical ischemia-reperfusion injury[2,3], potentially attenuating the efficacy of reperfusion therapies. This has provided impetus for identifying therapies which protect against ischemia-reperfusion injury. Acute interventions, including ischemic preconditioning and infusion of adenosinergic agents (including dipyridamole)[2-4], reduce ischemia-reperfusion injury in animal models and human myocardium. To date, continual protection against ischemia-reperfusion injury is not available for patients at high risk for MI who may require emergent reperfusion therapy.

Several lines of evidence suggest that nucleoside transport inhibitors, which increase extracellular adenosine levels by inhibiting uptake into myocytes and endothelial cells, might offer sustained or chronic protection against ischemia-reperfusion injury. We previously demonstrated that chronic exposure to ethanol, an adenosine uptake inhibitor, reduces ischemia-reperfusion injury in guinea 
pig hearts, requiring adenosine $\mathrm{A} 1$ receptor signaling and $\varepsilon \mathrm{PKC}$ translocation within the myocyte to effect cardioprotection[5,6]. While mechanistically interesting, the search for a safer therapy against ischemia-reperfusion injury was necessary. We subsequently found that regular dipyridamole therapy, a clinically usable nucleoside transport inhibitor, induces similar continual cardioprotection to that seen with chronic ethanol exposure, also mediated through adenosine A1 receptor activation[7].

As dipyridamole is clinically available, we asked whether chronic therapy with this adenosine uptake inhibitor produces continued protection against ischemia-reperfusion injury that lasted beyond 24 hours after the last dosing. We further sought to identify potential mechanisms underlying this sustained cardioprotective effect. We found that regular dipyridamole therapy protects against ischemia-reperfusion injury, a protective effect persisting for at least 3 days following the last dosing. This sustained protection was associated with continued increased expression of activated Akt and endothelial nitric oxide synthase (eNOS), known mediators of myocyte preconditioning signaling cascades. 


\section{Materials and Methods}

This study was conducted in accordance with the Guidelines for Animal Research at Osaka Dental University, and with the approval of the Animal Experiment Committee of Osaka Dental University, Osaka, Japan. These guidelines conform with the Guide for the Care and Use of Laboratory Animals from the National Academy of Sciences, Washington D.C, USA. Male Hartley guinea pigs were fed Lab Diet (RC4, Oriental Yeast, Tokyo, Japan) and given water ad libitum. Dipyridamole was added to the drinking water of the dipyridamole-treated guinea pigs $(11.4 \mathrm{mg} / \mathrm{l})$ for 6 weeks. Guinea pigs drink approximately $3.5 \mathrm{ml}$ water per $10 \mathrm{~g}$ of body weight per day, resulting in a dipyridamole intake of $4 \mathrm{mg} / \mathrm{kg} / \mathrm{day}$. This dose approximates the daily human dose of 75-100 mg four times daily. A diagram of the experimental protocol is shown in Figure 1.

Isolated Heart Perfusion and Measurement of Function

Male guinea pigs weighing 550-700g (12-13 weeks old) were given heparin (1000 units intraperitoneally), then anesthetized with pentobarbital $(60 \mathrm{mg} / \mathrm{kg}$, intraperitoneally). Hearts were excised and immediately arrested in cold iso-osmotic saline containing $20 \mathrm{mM} \mathrm{KCl}$. The aorta was cannulated and the isolated hearts were perfused at $70 \mathrm{mmHg}$ on a nonrecirculating isovolumic perfused heart apparatus, using a Krebs-Henseleit perfusate and paced at 240 beats/min as previously described.[5] Left ventricular developed pressure (LVDP; mmHg) was measured using a 2.5 French, high-fidelity micromanometer (Nihon-Kohden, Tokyo, Japan) passed into a compliant latex balloon, inserted into the left ventricle, and recorded on a PowerLab 2/20 Data Recording System (ADInstruments, Hayward, Australia). The balloon was connected to a Y-adapter with one end used to advance the micromanometer and the other used to fill the left ventricular balloon with bubble-free water to an end-diastolic pressure (LVEDP) of $10 \mathrm{mmHg}$. Coronary flow (CF) (ml/min) was measured by collecting effluent. Global ischemia was achieved by clamping the aortic inflow line. During ischemia, hearts were maintained at $37^{\circ} \mathrm{C}$ by enclosure 
in a water-jacketed air chamber. Warmed perfusate kept in the lower part of the chamber saturated the air with humidity and prevented cooling by evaporation. Heart temperature was continuously monitored by a digital thermometer (PTW-100A, Unique Medical, Tokyo, Japan).

\section{Experimental Protocol}

Forty guinea pigs were divided into 5 groups of eight each (see Figure 1). After a 20 min equilibration, baseline LVDP, LVEDP and CF were recorded. Eight hearts were subjected to 30 min of ischemia followed by $120 \mathrm{~min}$ of reperfusion (control; CTL). Ischemia-reperfusion was performed at $0,2,3$, and 4 days after discontinuation of dipyridamole in four additional groups of eight each (0Day, 2Days, 3Days and 4Days).

\section{Determination of Myocardial Infarct Size}

At the end of experiments, hearts were quickly frozen at $-80^{\circ} \mathrm{C}$ for $15 \mathrm{~min}$, and then sliced into $2 \mathrm{~mm}$ thick transverse sections from apex to base (6 slices/heart). After removing the right ventricle and defrosting, each slice was weighed and incubated at $37{ }^{\circ} \mathrm{C}$ with $1 \%$ triphenyltetrazolium chloride (Sigma Chemicals) in phosphate buffer ( $\mathrm{pH} \mathrm{7.4)} \mathrm{for} 10$ min and then fixed in $10 \%$ formalin for at least $5 \mathrm{~h}$ to distinguish red stained viable tissue from pale unstained necrotic tissue.[8] Each slice was photographed and the necrotic area was determined using Adobe Photoshop $^{\circledR}$ CS (Adobe, San Jose, CA, USA) and multiplied by the weight of the slice, then expressed as a fraction of the left ventricle.

\section{Western Blot Analysis}

Separate experiments were performed on eight additional hearts to examine expression of Akt and eNOS ( $\mathrm{n}=4$ for each group). Myocardial tissue samples were collected after 120min reperfusion, 
and homogenized in ice-cold homogenizing buffer containing $250 \mathrm{mM}$ sucrose, $20 \mathrm{mM}$ HEPES (pH 7.5), $10 \mathrm{mM} \mathrm{KCl,} 2 \mathrm{mM}$ EGTA, $2 \mathrm{mM} \mathrm{MgCl}_{2}, 25 \mathrm{mM} \mathrm{NaF}, 50 \mathrm{mM} \beta$-glycerophosphate, $1 \mathrm{mM}$ $\mathrm{Na}_{3} \mathrm{VO}_{4}, 1 \mathrm{mM}$ PMSF and protease inhibitor leupeptin $(10 \mu \mathrm{g} / \mathrm{ml})$. The homogenate was centrifuged at $1000 \mathrm{~g}$ for $5 \mathrm{~min}$ at $4{ }^{\circ} \mathrm{C}$ to clean up. The supernatant was re-centrifuged at $10000 \mathrm{~g}$ for $15 \mathrm{~min}$ at 4 ${ }^{\circ} \mathrm{C}$ to obtain cytosolic fraction. The protein concentration was estimated with a Bradford assay. Equivalent amounts $(20 \mu \mathrm{g})$ of protein samples were loaded and separated on a 10\% SDS-PAGE gradient gel, then electrically transferred overnight to a polyvinylidene difluoride membrane (Bio-Rad, Hercules, CA, USA). After blocking with 5\% skim milk in Tris-buffered saline containing $0.1 \%$ Tween-20 (TBS-T), the membranes were incubated for $2 \mathrm{~h}$ at $4{ }^{\circ} \mathrm{C}$ in TBS-T containing $5 \%$ skim milk and overnight 1:1000 dilution of rabbit primary antibody for phospho-Akt (Ser437; Cell Signaling Technology, Boston, MA), and phospho-eNOS (Ser177; Cell Signaling Technology, Boston, MA). Membranes were incubated with a 1:1000 dilution of horseradish peroxidase-labeled anti-rabbit immunoglobulin G (NA 934V, GE Healthcare, Buckinghamshire, United Kingdom). The same blot was stripped and re-blotted with antibodies to total-Akt, total-eNOS (Cell Signaling Technology, Boston, MA) and -tubulin (Santa Cruz Biotechnology) to confirm equal protein loading. Bound antibody signals were detected with enhanced chemiluminescence (Pierce Biotechnology, Rockford, IL) and visualized using VersaDoc 5000 Imaging System (Bio-Rad, Hercules, CA, USA). Quantitative analysis of the band densities was performed by Quantity One software (Bio-Rad), and the results are presented as the ratio of phospho-Akt and phospho-eNOS to total Akt and eNOS. The average light intensity was multiplied by 100 to facilitate presentation of an $x$-fold increase.

Statistical Analysis

All data are expressed as mean \pm SD. Statistical power analysis revealed that a sample size of $\mathrm{n}=8$ per group would provide sufficient power $(0.8)$ to detect a difference between mean infarct size 
indices of $15 \%$ ( $\mathrm{SD}=9, \alpha=0.05)$. A group size of $\mathrm{n}=4$ was used for Western blot to provide a power of 0.8 to detect a difference between means of $20 \%(\mathrm{SD}=10, \alpha=0.05)$. Hemodynamic data were tested for normal distribution and subsequently analyzed by a two-factor repeated-measures analysis of variance for time and treatment. If an overall difference between the variables was observed, comparisons were performed as one-way ANOVA followed by Tukey's post-hoc test for inter-group differences and by Dunnett's for intra-group differences with baseline values as the reference time point. Analyses of infarct size and Western blot were performed using one-way ANOVA followed by Student's t-test with Bonferroni's correction for multiple comparisons to avoid type I error. For changes within and between groups a two-tailed p value less than 0.05 was considered significant in advance. (SPSS17 for Windows, SPSS Japan, Tokyo, Japan). 


\section{RESULTS}

Regular Dipyridamole Therapy Improves Contractile Recovery During Post-Ischemic Reperfusion. Baseline LVDP, LVEDP and coronary flow were similar in perfused hearts from animals treated for six weeks with dipyridamole and age-matched controls (Table 1). LVDP recovery was significantly improved during post-ischemic reperfusion in hearts from animals treated with dipyridamole for 6 weeks compared to controls at 0Day, 2Days, 3Days, but not 4Days $(51 \pm 14$ $\mathrm{mmHg}, 49 \pm 15 \mathrm{mmHg}, 54 \pm 10 \mathrm{mmHg}, 43 \pm 10 \mathrm{mmHg}$ at 0Day, 2Days, 3Days and 4Days versus $27 \pm 6$ $\mathrm{mmHg}$ in controls, $\mathrm{p}<0.05$ for 0Day, 2Days, 3Days; Table 1). LVEDP rise, an indicator of myocardial contracture, was lower in hearts from dipyridamole-treated animals compared to controls at 0Day, 2Days, 3Days, but not 4Days $(23 \pm 13 \mathrm{mmHg}, 23 \pm 10 \mathrm{mmHg}, 26 \pm 18 \mathrm{mmHg}$, $35 \pm 11 \mathrm{mmHg}$ at 0 Day, 2Days, 3Days and 4Days versus $52 \pm 24 \mathrm{mmHg}$ in controls, $\mathrm{p}<0.05$ for 0 Day, 2Days, and 3Days; Table 1). These data suggest that dipyridamole therapy for 6 weeks improved contractile recovery and reduced the degree of contracture or irreversible myocardial injury after ischemia-reperfusion for at least 3 days after discontinuation of therapy. There were no differences in coronary flow or coronary perfusion pressure before or after ischemia-reperfusion in dipyridamole versus control hearts (Table 1). This suggests that differences in coronary flow cannot account for the improved contractile recovery after ischemia-reperfusion in hearts from animals chronically treated with dipyridamole.

Regular Dipyridamole Therapy Reduces Infarct Size. Myocardial infarct size data are shown in Figure 2. Myocardial infarct size in hearts from animals treated with dipyridamole were significantly reduced by approximately $50 \%$ compared with control hearts at 0Day, 2Days, and 3Days, but not 4Days $(22 \pm 12 \%, 22 \pm 5 \%, 22 \pm 6 \%, 37 \pm 8 \%$ at 0Day, 2Days, 3Days and 4Days versus $42 \pm 5 \%$, controls, $\mathrm{p}<0.05$ for 0Day, 2Days, and 3Days; Table 1). 
Cardioprotection by Dipyridamole Persists After Discontinuation of Treatment: The effects of discontinuing regular dipyridamole therapy on contractile recovery and infarct size after ischemia-reperfusion are shown in Table 1 and Figure 2. Cardioprotection from chronic dipyridamole treatment persisted for at least three days after discontinuation of treatment. By the fourth day this cardioprotection began to dissipate, as evidenced by a non-significant improvement in contractile functional recovery (LVEDP) and infarct size.

Persistent Dipyridamole-Induced Protection Against Ischemia-Reperfusion Injury is Associated with Activated Akt and eNOS Expression: As shown in Figure 3, expression of activated Akt and activated eNOS were elevated in hearts from dipyridamole-treated animals when compared to control hearts. These increased expressions of activated Akt and activated eNOS persisted for at least three days after discontinuation of dipyridamole treatment. These persistent expressions of potential preconditioning mediators coincided with the time course after discontinuation of dipyridamole treatment of decreased infarct size and improved hemodynamics following ischemia-reperfusion. 


\section{DISCUSSION}

The major finding of this study is that regular dipyridamole therapy produces sustained or chronic protection against ischemia-reperfusion injury in guinea pig hearts that persists for at least 3 days after discontinuing treatment. Furthermore, increased activated Akt and activated eNOS expression coincide with this persistent cardioprotection and may play a role in mediating this chronic preconditioning-like effect. There is currently no therapy available to induce chronic cardioprotection against ischemia-reperfusion injury in patients at high risk for MI who may require emergent reperfusion therapy. Understanding the mechanisms underlying this persistent cardioprotective effect of regular dipyridamole treatment may help in the development of therapies to protect these at risk patients.

Acute dipyridamole therapy mimics ischemic preconditioning and has been shown to enhance the protective effect of preconditioning against ischemia-reperfusion injury[9]. Acute exposure to other nucleoside transport inhibitors, including dilazep[10] and ethanol[11], also mimic or enhance the protective effect of ischemic preconditioning against ischemia-reperfusion injury.

We previously demonstrated that regular exposure to ethanol (daily for as little as 3 weeks), an adenosine uptake inhibitor[12], produced sustained cardioprotection against ischemia-reperfusion injury[5,6]. This preconditioning-like effect of regular ethanol treatment was attenuated in the presence of selective adenosine A1 receptor antagonism[5]. Further, this ethanol-induced cardioprotection persisted for at least seven days after discontinuing ethanol consumption[13]. Interestingly, epidemiological data are consistent with these observations; regular drinkers have improved outcomes after acute MI when compared to abstainers[14,15]. Unfortunately, it is not safe to recommend the cardioprotective effects of ethanol consumption given the risks for abuse and 
alcoholic-related diseases. Furthermore, ethanol, no doubt, has pleotropic effects beyond its inhibition of adenosine reuptake, which may have detrimental effects on the heart, especially with heavy consumption. Therefore, we sought to determine whether regular dipyridamole therapy, a safer adenosine uptake inhibitor, produced a similar chronic preconditioning-like effect[7].

Although the potential benefits of regular dipyridamole therapy in protecting against ischemia-reperfusion injury have not been examined clinically, dipyridamole has been already studied as potential therapy to reduce the risk of re-infarction in patients after MI[1]. In the Persantine-Aspirin Reinfarction Study (PARIS), the efficacy of the combination of dipyridamole and aspirin, aspirin alone, or placebo in preventing subsequent cardiac events in patients who had previously suffered an MI was examined[1]. Dipyridamole and aspirin produced no statistically significant additional benefit on total mortality, coronary mortality, or nonfatal MI compared to aspirin alone (subgroup analysis did show that subjects less than 6 months from their previous MI benefited from combination therapy). However, the PARIS trial was performed in the pre-thrombolytic era. In this era of emergent reperfusion therapies, potential chronic preconditioning therapies require re-examination.

No therapy is yet available which produces a sustained preconditioned state. Cohen and colleagues reported that the cardioprotective effect of ischemic preconditioning in rabbits (40 to 65 five min occlusive episodes) waned after 3 to 4 days[16]. Dana et al., demonstrated that a preconditioned state could be maintained in rabbits for at least 10 days using intermittent, not continuous, infusion of an adenosine A1 agonist 2-chloro- $\mathrm{N}^{6}$-cyclopentyladenosine (CCPA)[17]. While activation of cardioprotection by regular dipyridamole therapy, intermittent CCPA or acute ischemic preconditioning may be mediated similarly at the time of ischemia (e.g., via adenosine A1 receptor activation), chronic dipyridamole therapy may induce more lasting responses that produce 
sustained protection which are not maintained by continued ischemic preconditioning. For example, we found that chronic exposure to ethanol causes sustained translocation and activation of epsilon protein kinase $\mathrm{C}(\varepsilon \mathrm{PKC})$ in myocytes[6], a $\mathrm{PKC}$ isozyme implicated in ischemic preconditioning[18]. When regular treatment with an adenosine uptake inhibitor produces sustained $\varepsilon \mathrm{PKC}$ translocation to its site of activation[6], and $\varepsilon \mathrm{PKC}$ is then triggered by the adenosine A1 receptor signaling cascade at the time of ischemia, $\varepsilon \mathrm{PKC}$ is already primed to open sarcolemmal and mitochondrial adenosine triphosphate-sensitive potassium channels ( mitoK $_{\text {ATP }}$ ), shown to play a role in reducing infarct size in ischemic and ethanol preconditioning[11].

Cardiac myocytes express eNOS which regulates myocardial contractile function and oxygen consumption[19]. Nitric oxide is an important mediator in cardioprotection, activating mitoK ${ }_{\text {ATP }}[20]$. Knockout mice lacking eNOS suffer larger infarcts than wild type after ischemia[21]. Overexpression of eNOS in mice attenuates myocardial ischemia-reperfusion injury[22]. In our study, increased activated eNOS expression coincided with the persistent dipyidamole-induced cardioprotection for at least three days after discontinuation of therapy. We previously reported on persistent cardioprotection by chronic ethanol consumption after abstention and the potential role of activated eNOS in that persistent cardioprotection model[13].

Preventing mPTP opening by inhibiting glycogen synthase kinase 3 (GSK-3) has been shown to play a role in ischemic preconditioning[24]. Irreversible mPTP opening abolishes the mitochondrial membrane potential, disabling ATP production. GSK-3 is a substrate for multiple pro-survival protein kinases, including Akt. Inhibiting GSK-3 by PI3/Akt signaling is a key event in preventing mPTP opening, increasing cell survival[25]. Zhong et al., reported that mice fed $18 \%$ ethanol in their drinking water for 12 weeks demonstrated sustained translocation of -PKC, as well as increased Akt expression[26]. In our study, increased activated Akt expression coincided with 
persistent dipyidamole-induced cardioprotection for at least three days after discontinuation of therapy.

There is currently no therapy available to induce sustained protection against ischemia-reperfusion injury in patients at high risk for MI who may require emergent reperfusion therapy. Our data suggest that regular dipyridamole therapy produces sustained protection against ischemia-reperfusion injury, lasting up to three days after discontinuation of treatment. Furthermore, increased activated Akt and activated eNOS expression coincide with this persistent cardioprotection and may play a role in mediating this chronic preconditioning-like effect. Future studies will determine how chronic exposure to adenosine uptake inhibitors produce this delayed, yet sustained, preconditioning state. 


\section{ACKNOWLEDGEMENTS}

This study was conducted at the Laboratory Animal Facilities and Dental Bioscience I, Institute of Dental Research, Osaka Dental University, and was supported by a Grant-in-Aid for Scientific Research (C) 26463081 from the Ministry of Education, Culture, Sports, Science and Technology of Japan (Masami Miyamae). 


\section{REFERENCES}

1. Persantine and aspirin in coronary heart disease. The Persantine-Aspirin Reinfarction Study Research Group. Circulation 62: 449-61, 1980.

2. Fröhlich GM, Meier P, White SK, Yellon DM, Hausenloy DJ. Myocardial reperfusion injury: looking beyond primary PCI. Eur Heart J. 2013 Jun;34(23):1714-22.

3. Hausenloy DJ, Yellon DM. Myocardial ischemia-reperfusion injury: a neglected therapeutic target. J Clin Invest. 2013 Jan 2;123(1):92-100.

4. Kloner RA. Current state of clinical translation of cardioprotective agents for acute myocardial infarction. Circ Res. 2013 Aug 2;113(4):451-63.

5. Miyamae M. Diamond I, Weiner MW, Camacho SA, and Figueredo VM. Regular alcohol consumption mimics cardiac preconditioning by protecting against ischemia-reperfusion injury. Proc Natl Acad Sci U S A 94: 3235-9, 1997.

6. Miyamae M, Rodriguez MM, Camacho SA, Diamond I, Mochly-Rosen D, and Figueredo VM. Activation of epsilon protein kinase $\mathrm{C}$ correlates with a cardioprotective effect of regular ethanol consumption. Proc Natl Acad Sci U S A 95: 8262-7, 1998.

7. Figueredo VM, Diamond I, Zhou HZ, Camacho SA. Chronic dipyridamole therapy produces sustained protection against cardiac ischemia-reperfusion injury. Am J Physiol. 1999 Nov;277(5 Pt 2):H2091-7.

8. Fishbein MC, Meerbaum S, Rit J, Lando U, Kanmatsuse K, Mercier JC, Corday E, Ganz W. Early phase acute myocardial infarct size quantification: validation of the triphenyl tetrazolium chloride tissue enzyme staining technique. Am Heart J. 1981;101:593-600. 
9. Gokgoz L, Soncul H, Sinci V, Karasu C, Kaptanoglu M, Yener A, Ersoz A. Dipyridamole induced myocardial recovery after global ischemia. Gen Pharmacol 23: 435-7, 1992.

10. Itoya M, Miura T, Sakamoto J, Urabe K, Iimura O. Nucleoside transport inhibitors enhance the infarct size-limiting effect of ischemic preconditioning. J Cardiovasc Pharmacol 24: 846-52, 1994.

11. Miyamae M, Kaneda K, Domae N, Figueredo VM. Cardioprotection by regular ethanol consumption: potential mechanisms and clinical application. Curr Drug Abuse Rev. 2010 Mar;3(1):39-48.

12. Nagy LE, Diamond I, Casso DJ, Franklin C, Gordon AS. Ethanol increases extracellular adenosine by inhibiting adenosine uptake via the nucleoside transporter. J Biol Chem. 1990 Feb $5 ; 265(4): 1946-51$.

13. Kaneda K, Miyamae M, Sugioka S, Okusa C, Inamura Y, Onishi A, Domae N, Figueredo VM, Kotani J. Persistent Cardioprotection by Regular Ethanol Consumption After Abstention Depends on eNOS but not iNOS Activity After Reperfusion. Circulation 2008;118:3889(S498).

14. Wannamethee G, Whincup PH, Shaper AG, Walker M, MacFarlane PW. Factors determining case fatality in myocardial infarction "who dies in a heart attack"? Br Heart $J$ 74: 324-31, 1995.

15. Dufour MC, Caces MF, Whitmore CC, Hanna EZ. Alcohol consumption and death from acute myocardial infarction in a national longitudinal cohort. Alcohol Clin Exp Res 20: 97A (abstract), 1996.

16. Cohen MV, Yang XM, Downey JM. Conscious rabbits become tolerant to multiple episodes of ischemic preconditioning. Circ Res 74: 998-1004, 1994. 
17. Dana A, Baxter G, Walker J, Yellon D. Prolonging the delayed phase of myocardial protection: repetitive adenosine $\mathrm{A} 1$ receptor activation maintains rabbit myocardium in a preconditioned state. J Am Coll Cardiol. 1998 Apr;31(5):1142-9.

18. Gray MO, Karliner JS, Mochly-Rosen D. A selective epsilon protein kinase C antagonist inhibits protection of cardiac myocytes from hypoxia-induced cell death. J Biol Chem $1997 ; 272(49): 30945-51$.

19. Heusch G, Post H, Michel MC, Kelm M, Schulz R. Endogenous nitric oxide and myocardial adaptation to ischemia. Circ Res 2000;87:146-52.

20. Sasaki N, Sato T, Ohler A, O'Rourke B, Marban E. Activation of mitochondrial ATP-dependent potassium channels by nitric oxide. Circulation 2000; 101: 439-45.

21. Sumeray MS, Rees DD, Yellon DM. Infarct size and nitric oxide synthase in murine myocardium. J Mol Cell Cardiol 2000; 32: 35-42.

22. Jones SP, Greer JJ, Kakkar AK, Ware PD, Turnage RH, Hicks M, van Haperen R, de Crom R, Kawashima S, Yokoyama M, Lefer DJ. Endothelial nitric oxide synthase overexpression attenuates myocardial reperfusion injury. Am J Physiol Heart Circ Physiol 2004; 286: H276-82.

23. Miura T, Miki T. GSK-3beta, a therapeutic target for cardiomyocyte protection. Circ J 2009; 73: 1184-92.

24. Juhaszova M, Zorov DB, Kim SH et al. Glycogen synthase kinase-3beta mediates convergence of protection signaling to inhibit the mitochondrial permeability transition pore. J Clin Invest 2004; 113: 1535-49.

25. Zhou HZ, Karliner JS, Gray MO. Moderate alcohol consumption induces sustained cardiac protection by activating PKC-epsilon and Akt. Am J Physiol Heart Circ Physiol 2002; 283 : H165-74. 


\section{FIGURE LEGENDS}

Figure 1. Schematic illustration of experimental protocol. All hearts were subjected to 30 min of global ischemia followed by 120 min of reperfusion. Dipyridamole-treated guinea pigs received 4 $\mathrm{mg} / \mathrm{kg} /$ day dipyridamole in their drinking water for 6 weeks. Ischemia-reperfusion was performed at 0, 2, 3, and 4 days after discontinuation of dipyridamole (0Day, 2Days, 3Days and 4Days; $\mathrm{n}=8$ for each group). Tissue samples were obtained at baseline and $120 \mathrm{~min}$ after reperfusion ( $\mathrm{n}=4$ for each group).

Figure 2. Infarct size as a percentage of the left ventricle. Myocardial infarct size was significantly reduced in 0Day, 2Days and 3Days, but not 4Days, compared to control $(22 \pm 12 \%, 21 \pm 5 \%, 22 \pm 6 \%$, $37 \pm 8 \%$ at 0 Day, 2Days, 3Days and 4Days versus control $42 \pm 5 \%$, $* \mathrm{p}<0.05$ for 0Day, 2Days, 3Days; $n=8$ for each group).

Figure 3. Western blot analyses of inducible endothelial nitric oxide synthase (eNOS) and Akt from left ventricular samples in hearts from control and dipyridamole-treated animals. In the dipyridamole group (except 4Days), expression of activated eNOS and Akt were significantly increased compared with control at baseline (A) and after 120 min reperfusion (B). Data are presented as mean \pm SD. $* \mathrm{p}<0.05$ vs. CTL, $\mathrm{n}=4$ for each group

\section{Table 1.}

Data are presented as mean \pm SD. $*$ p $<0.05$ vs. CTL $n=8$ each group

LVDP = left ventricular developed pressure; $\mathrm{LVEDP}=$ left ventricular end-diastolic pressure $; \mathrm{CF}=$ coronary flow

Figure 1 


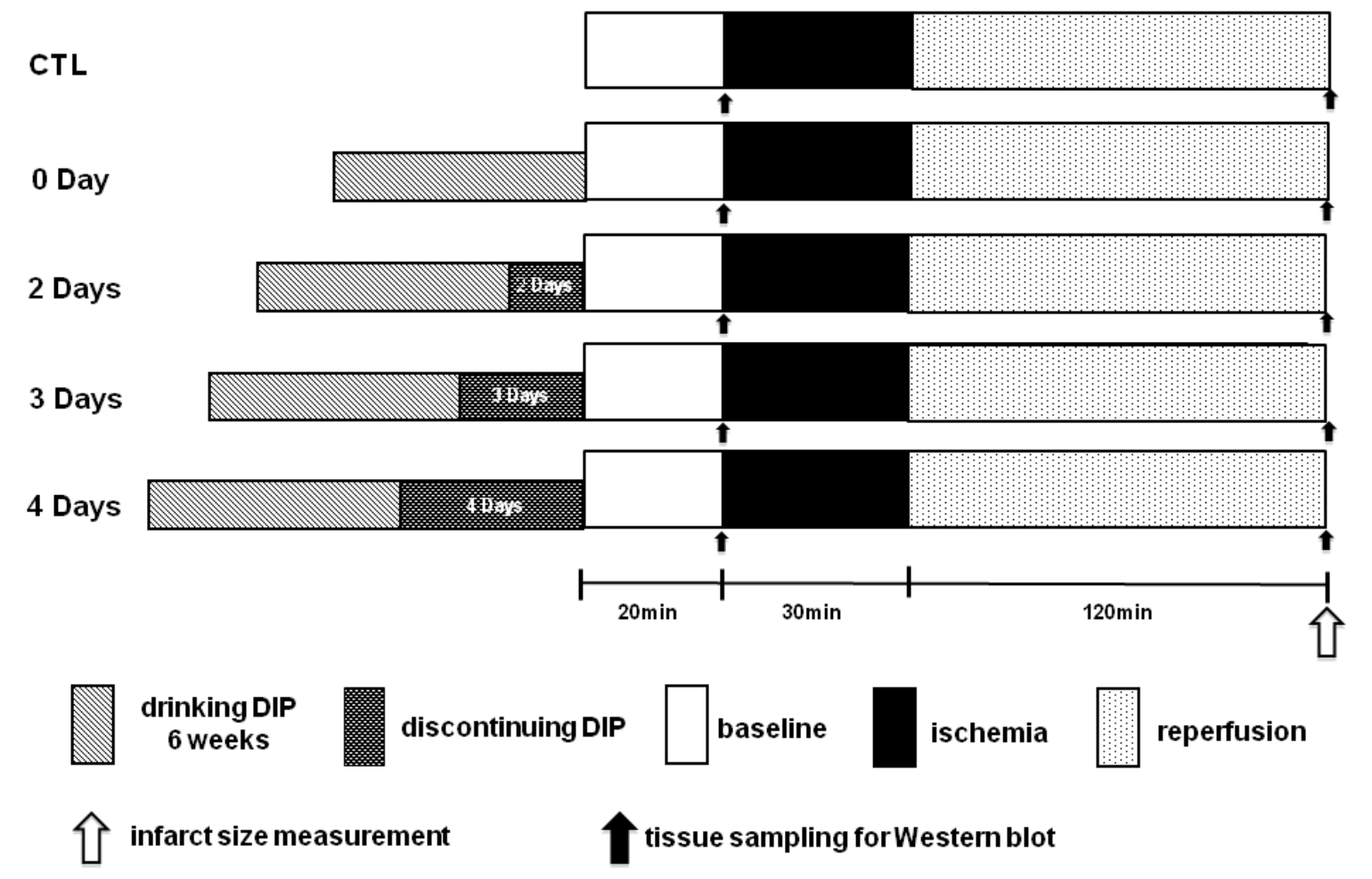


Figure 2

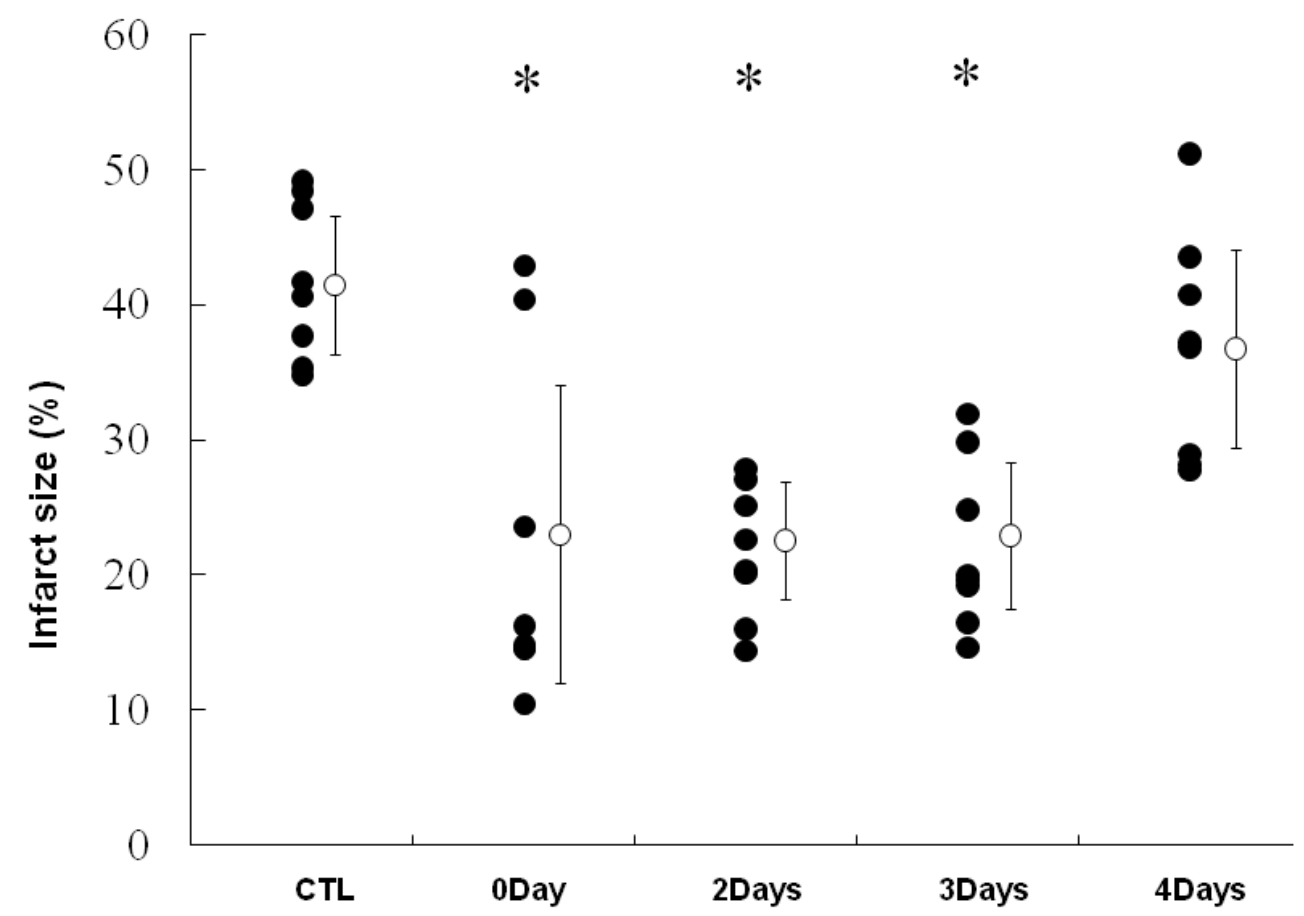


Figure 3A

(A) baseline
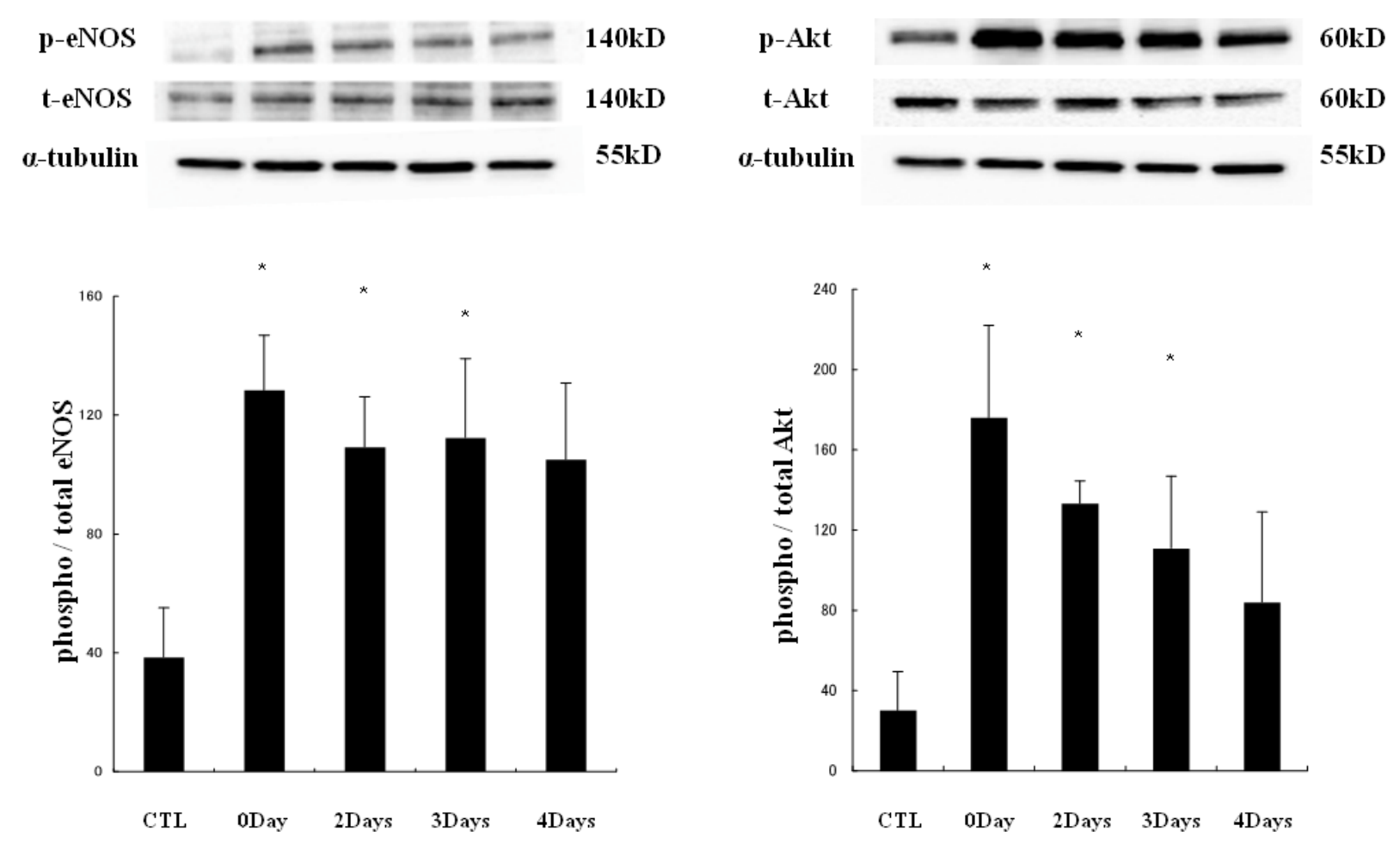
Figure 3B

\section{(B) rep $120 \mathrm{~min}$}
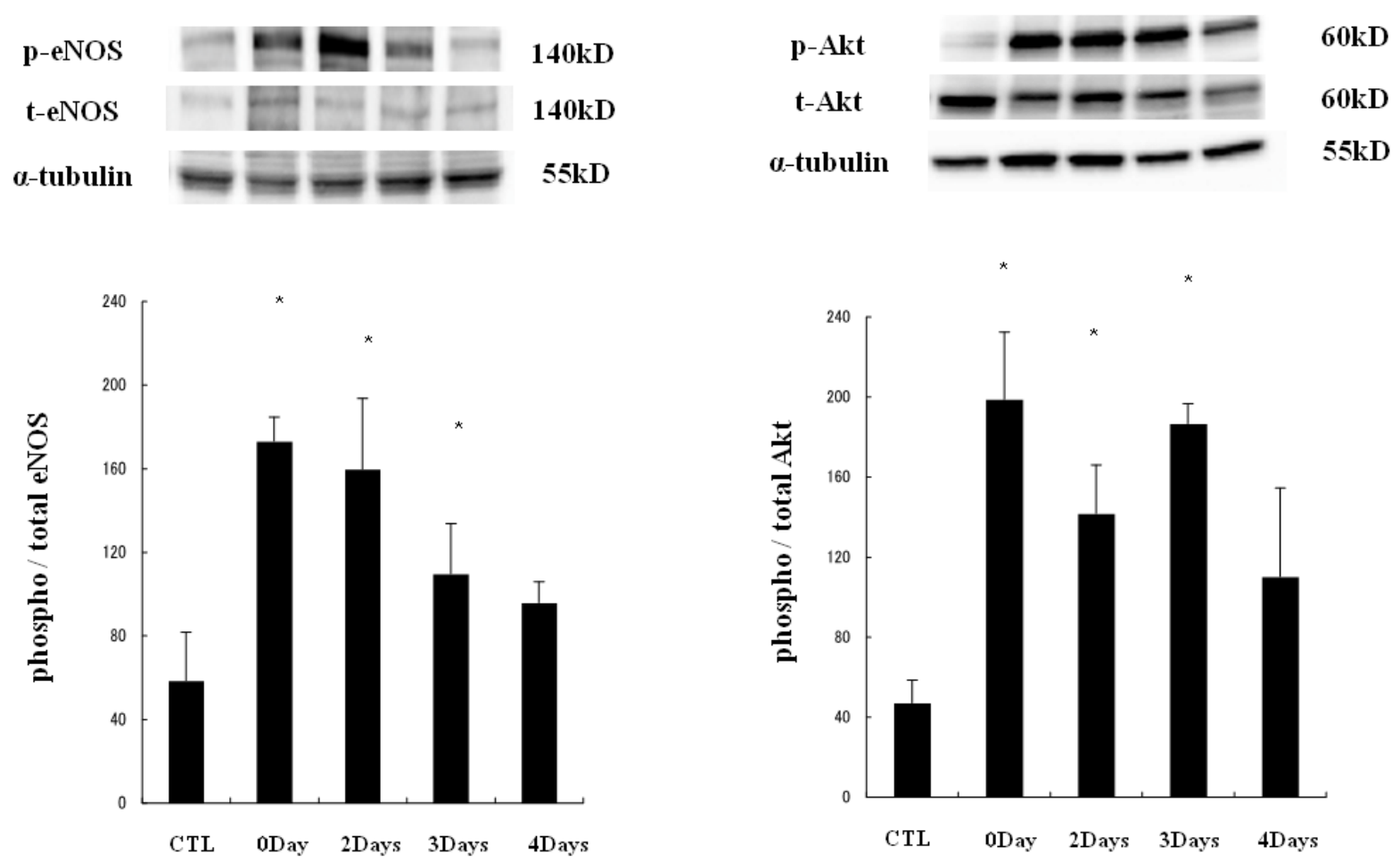
Table 1

\begin{tabular}{|c|c|c|c|c|c|c|}
\hline & \multicolumn{3}{|c|}{ Baseline } & \multicolumn{3}{|c|}{ 120min Reperfusion } \\
\hline & LVDP $(\mathrm{mmH}$ & $\mathrm{P}(\mathrm{mn}$ & $\mathrm{CF}(\mathrm{mL} / \mathrm{min})$ & LVDP & LVEDP & $\mathrm{CF}$ \\
\hline$\overline{\mathrm{CTL}}$ & $112 \pm 16$ & $10 \pm 1$ & $28 \pm 7$ & $27 \pm 6$ & $52 \pm 24$ & $22 \pm 9$ \\
\hline ODay & $101 \pm 16$ & $10 \pm 0$ & $26 \pm 8$ & $51 \pm 14^{*}$ & $23 \pm 13^{*}$ & $20 \pm 10$ \\
\hline 2Days & $103 \pm 9$ & $10 \pm 0$ & $28 \pm 8$ & $49 \pm 15^{\circ}$ & $23 \pm 10^{\circ}$ & $20 \pm 6$ \\
\hline 3Days & $100 \pm 19$ & $10 \pm 0$ & $32 \pm 7$ & $54 \pm 10^{\circ}$ & $26 \pm 18^{*}$ & $23 \pm 12$ \\
\hline 4Days & $107 \pm 12$ & $10 \pm 0$ & $27 \pm 4$ & $43 \pm 10$ & $35 \pm 11$ & $19 \pm 10$ \\
\hline
\end{tabular}

